\title{
Improvement of thermal stability of Ta-N film in Cu metallization by a Zr-Si interlayer
}

\author{
Yannan $\mathrm{ZHAI}^{1, \mathrm{a}}$, Zhaoxin $\mathrm{WANG}^{1}$, Hui ZHANG ${ }^{1}$, Ling GAO ${ }^{1}$, Changhong $\mathrm{DING}^{1}$ \\ ${ }^{1}$ Aviation University Air Force ,130022 Changchun Jilin China
}

\begin{abstract}
Ta-N (10 nm)/Zr (20 nm) film was grown on n-type (100) silicon wafer at various substrate temperatures in a rf magnetron sputtering system, followed by in situ deposition of $\mathrm{Cu}$. The $\mathrm{Cu} / \mathrm{Ta}-\mathrm{N} / \mathrm{Zr} / \mathrm{Si}$ samples were subjected to thermal annealing up to $800{ }^{\circ} \mathrm{C}$ under the protection of pure nitrogen gas. In order to investigate the effect of insertion of a thin $\mathrm{Zr}$ layer under Ta-N film on Ta-N diffusion barrier performance in $\mathrm{Cu}$ metallization, $\mathrm{Cu} / \mathrm{Ta}-\mathrm{N} / \mathrm{Zr} / \mathrm{Si}$ contact system was characterized by $\mathrm{X}$-ray diffraction (XRD), four-point probe (FPP) measurement, scanning electron microscopy (SEM), and Auger electron spectroscopy (AES) depth profile. The results reveal that the microstructure of Ta-N films deposited on $\mathrm{Zr}$ is amorphous at different substrate temperatures. The barrier breakdown temperature of Ta-N/Zr film is about $100^{\circ} \mathrm{C}$ higher than that of Ta-N. It can effectively prevent the diffusion of $\mathrm{Cu}$ after annealed at $800^{\circ} \mathrm{C}$. The improvement of diffusion barrier performance may be due to the production of $\mathrm{Zr}$-Si layer with low contact resistivity after annealed at $800^{\circ} \mathrm{C}$.
\end{abstract}

\section{Introduction}

Copper metallization has become very popular in the $\mathrm{Si}$ industry. $\mathrm{Cu}$ possesses significant advantages over $\mathrm{Al}$ in terms of RC delay and electromigration ${ }^{[1,2]}$. However, $\mathrm{Cu}$ reacts with oxides, silicon, and silicides and it is a fast diffuser in these materials due to its high mobility. Therefore, it is necessary to insert a stable diffusion barrier between $\mathrm{Cu}$ and $\mathrm{Si}$ substrate. Binary transition metal nitrides, especially $\mathrm{TaN}^{[3-7]}$ has been widely investigated and used as diffusion barriers for $\mathrm{Cu}$ metallization in ULSI devices owing to its high melting point, high thermal stability and good adhesion characteristics. However, the resistivity of TaN is high $(180-270 \mu \Omega \cdot \mathrm{cm})^{[8,9]}$, therefore, TaN barrier may not well satisfy the need of high speed processing in copper metallization.

Zirconium silicide/silicon interface is a low resistance Ohmic contact and the barrier height $(0.55 \mathrm{eV})$ between the $\mathrm{Zr}$ silicide and silicon shows that this contact may be useful for both $n$-and $p$-type regions ${ }^{[10]}$. In addition, Zirconium silicide has a lower resistivity (about $50 \mathrm{~nm}$ thick, $32 \mu \Omega \cdot \mathrm{cm}$ ) ${ }^{[11]}$ than Ta-N. Cheng and chen have shown that an $\mathrm{Zr}-\mathrm{Si}$ interlayer was observed just after $\mathrm{Zr}$ deposition, increasing in thickness by low temperature annealing below $500{ }^{\circ} \mathrm{C}^{[12]}$. Wang has shown that a reactively sputtered $\mathrm{Zr}-\mathrm{Si}$ resulted in a promising diffusion barrier for copper metallization ${ }^{[13]}$. Therefore, in this work, in order to increase the failure temperature and decrease the resistivity of $\mathrm{Ta}-\mathrm{N}$ diffusion barrier, we developed a new Ta-N/Zr diffusion barrier, investigated its thermal stability in $\mathrm{Cu}$ metallization.

\section{Experimental}

A mirror-polished n-type (100) silicon wafer with resistivity of 3-5 $\Omega . \mathrm{cm}$ was cut into $20 \times 20 \mathrm{~mm} 2$ pieces and used as substrates. The wafers were progressively cleaned in an ultrasonic bath with acetone, methanol, isopropyl alcohol, and diluted HF solution and then rinsed in de-ionized water before the activation process, in order to remove organic contaminants and native oxide. After cleaning, the Si substrates were loaded in the radio frequency magnetron sputtering chamber that was maintained at a base pressure of $2 \times 10-5 \mathrm{~Pa}$. The distance between the target and substrate holder was fixed at $80 \mathrm{~mm}$. The sputtered targets were $\operatorname{Zr}(99.9 \%$ purity, $\varnothing 60 \mathrm{~mm} \times 3 \mathrm{~mm})$, Ta $(99.9 \%$ purity, $\varnothing 60 \mathrm{~mm} \times 3$ $\mathrm{mm})$ and $\mathrm{Cu}(99.9 \%$ purity, $\varnothing 60 \mathrm{~mm} \times 3 \mathrm{~mm})$. Both $\mathrm{N} 2$ and $\mathrm{Ar}$ gas purity were $99.999 \%$. A $\mathrm{Zr}$ layer was deposited by Ar ion sputtering, the sputtering power used for $\mathrm{Zr}$ target was $100 \mathrm{~W}$ and the flow rate of Ar was $20 \mathrm{sccm}$. The sputtering pressure was $0.3 \mathrm{~Pa}$. TaN film was deposited on the top of $\mathrm{Zr}$ layer by $\mathrm{RF}$ reactive sputtering in a mixture of $\mathrm{N} 2$ and $\mathrm{Ar}$ and the gas flowrate of $\mathrm{N} 2 / \mathrm{Ar}$ was $2 / 48 \mathrm{sccm}$, the sputtering power used for Ta target was $100 \mathrm{~W}$ and the sputtering pressure was $0.3 \mathrm{~Pa}$. The thickness of $\mathrm{Zr}$ and $\mathrm{Ta}-\mathrm{N}$ films were maintained at 20 and $10 \mathrm{~nm}$, respectively, by varying deposition time. After deposition of the barrier layers, $\mathrm{Cu}(100 \mathrm{~nm})$ film was deposited on the barriers without breaking vacuum at the sputtering pressure of $0.1 \mathrm{~Pa}$, the sputtering power used for $\mathrm{Cu}$ target was $90 \mathrm{~W}$ and the flowrate of Ar was $20 \mathrm{sccm}$. The substrate's negative bias was fixed at $-100 \mathrm{~V}$ during the whole deposited

$\overline{{ }^{a} \text { Corresponding author: 21548186@qq.com }}$ 
process. The samples were subsequently annealed at different temperatures ranging from 600 to $800^{\circ} \mathrm{C}$ in $\mathrm{N} 2$ ambient for $1 \mathrm{~h}$.

The sheet resistance was measured by 4-point probe (FPP) for the as-deposited and annealed films. The phase formation was investigated by X-ray diffraction (XRD). The surface topographies of films were inspected by scanning electron microscopy (SEM) and atomic force microscopy (AFM). The element profiles in depth of the as-deposited and annealed samples of $\mathrm{Cu} / \mathrm{Ta}-\mathrm{N}(10$ $\mathrm{nm}) / \operatorname{Zr}(20 \mathrm{~nm}) / \mathrm{Si}$ were identified by Auger electron spectroscopy (AES).

\section{Results and discussion}

\subsection{Microstructure of Ta-N/Zr films}

Fig. 1 shows the XRD pattern for the Ta-N(10 nm)/Zr(20 $\mathrm{nm})$ films deposited at different substrate temperatures. There are only obvious $\mathrm{Zr}$ diffraction peaks in the XRD spectrum for the Ta-N(10 nm)/Zr(20 nm) films deposited with different temperatures. No TaN diffraction peaks can be observed, which indicates the typical amorphous structure of the TaN film deposited on $\mathrm{Zr}$ film.

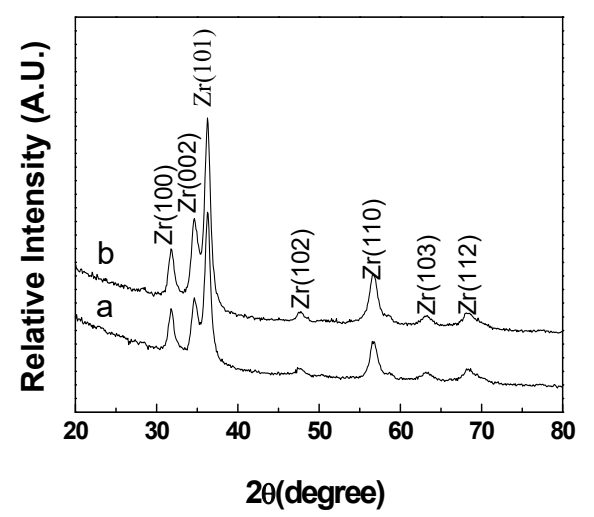

Fig.1. XRD patterns of Ta-N(10 nm)/Zr(20 nm)/Si samples deposited at various temperatures: (a) $100{ }^{\circ} \mathrm{C}$ and (b) $300{ }^{\circ} \mathrm{C}$

The surface morphology of barrier must be considered seriously because it will directly influence the adhesion strength between barrier and $\mathrm{Cu}$ film and barrier properties. It is believed the smoother surface of barrier is, the better barrier capability is ${ }^{[14]}$. Fig. 2 shows the surface morphology of as-deposited $\mathrm{Zr} / \mathrm{Si}$ and $\mathrm{Ta}-$ $\mathrm{N} / \mathrm{Zr} / \mathrm{Si}$ specimens. It can be observed from Fig.2(a) that the surface of $\mathrm{Zr}$ film is generally smooth with the surface root mean square (RMS) roughness equal to $2.997 \mathrm{~nm}$. For as-deposited Ta-N/Zr/Si specimens Fig.2(b), the surface root mean square (RMS) roughness decreases to $2.011 \mathrm{~nm}$. The average grain size of $\mathrm{Zr}$ film is $18.891 \mathrm{~nm}$, which is larger than that of Ta-N/Zr film $(12.742 \mathrm{~nm})$. This may be attributed to different microstructure of $\mathrm{Zr}$ and $\mathrm{Ta}-\mathrm{N}$ films. $\mathrm{Zr}$ film is polycrystalline structure with larger grain size and Ta-N film is amorphous structure with thin grain size. So the surface of $\mathrm{Ta}-\mathrm{N} / \mathrm{Zr}$ is smoother than that of $\mathrm{Zr}$ film. It is clear that Ta-N/Zr film with low roughness can well meet the requirement of barrier performance.
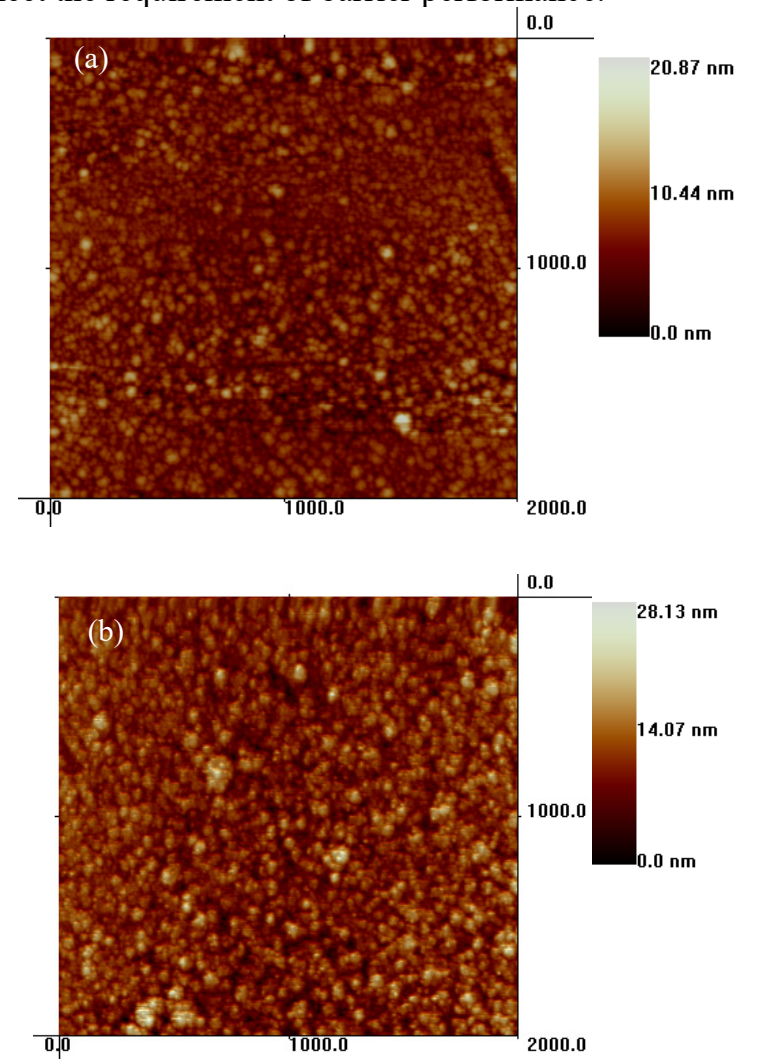

Fig.2. AFM micrographs of as-deposited samples: (a) $\mathrm{Zr} / \mathrm{Si}$ and (b) $\mathrm{Ta}-\mathrm{N} / \mathrm{Zr} / \mathrm{Si}$

\subsection{Barrier performance of $\mathrm{Ta}-\mathrm{N} / \mathrm{Zr}$ thin films}

Before annealing, the sheet resistance of the $\mathrm{Cu} / \mathrm{Ta}$ $\mathrm{N} / \mathrm{Zr} / \mathrm{Si}$ system is measured (recorded as Rs). After annealing, the sheet resistance of the sample is measured again and is recorded as Rf. Since the diffusion barrier is very thin, the sheet resistance of the $\mathrm{Cu} / \mathrm{Ta}-\mathrm{N} / \mathrm{Zr} / \mathrm{Si}$ structure mainly reflects the resistance of $\mathrm{Cu}$. The difference of sheet resistance between the annealed and as-deposited samples (Rf-Rs), which is divided by the sheet resistance of as-deposited samples, is called the variation percentage of sheet resistance $[15,16]$. Fig.3 shows the variation percentage of sheet resistance with annealing temperature of the $\mathrm{Cu} / \mathrm{Ta}-\mathrm{N} / \mathrm{Zr} / \mathrm{Si}$ structures. For comparison, that of the $\mathrm{Cu}(100 \mathrm{~nm}) / \mathrm{TaN}(30 \mathrm{~nm}) / \mathrm{Si}$ structures deposited are also shown in Fig.3. The resistivity of the as-deposited $\mathrm{Cu}$ film is about 5.4 $\mu \Omega . c m$, which is higher than the bulk value (bulk value:1.678 $\mu \Omega . \mathrm{cm}$ ). For all of samples, the variation percentage of sheet resistance is a downward trend with the increased annealing temperatures up to $700{ }^{\circ} \mathrm{C}$. This decrease was attributed to the grain growth and defect annihilation of the $\mathrm{Cu}$ layer during annealing because the sensing current mainly represents the status of the $\mathrm{Cu}$ film. For the $\mathrm{Cu} / \mathrm{Ta}-\mathrm{N}(30 \mathrm{~nm}) / \mathrm{Si}$ sample, annealing at $750{ }^{\circ} \mathrm{C}$ results in an abrupt increase in the variation percentage of sheet resistance, indicating a significant reaction involving the $\mathrm{Cu}$ layer. It may be caused by copper penetration through the $\mathrm{Ta}-\mathrm{N}$ layer into $\mathrm{Si}$ substrate and reaction with $\mathrm{Si}$. However, the sheet 
resistance for $\mathrm{Cu} / \mathrm{Ta}-\mathrm{N}(10 \mathrm{~nm}) / \mathrm{Zr}(20 \mathrm{~nm}) / \mathrm{Si}$ sample annealed at $800^{\circ} \mathrm{C}$ is still lower than that of the asdeposited sample. Fig.3 indicates clearly that the insertion of a $\mathrm{Zr}$ layer under Ta-N layer can effectively improve the thermal stability of Ta-N film.

Fig. 4 shows the XRD spectra of the $\mathrm{Cu} / \mathrm{Ta}-\mathrm{N}(10$ $\mathrm{nm}) / \mathrm{Zr} \quad(20 \mathrm{~nm}) / \mathrm{Si}$ structures at different annealing temperatures. The results show that peaks from only $\mathrm{Cu}$ and $\mathrm{ZrSi} 2$ are identified until annealing at $800{ }^{\circ} \mathrm{C}$. After annealing at this temperature, grain growth of the $\mathrm{Cu}$ film is evidently observed from higher intensity and narrower full width at half maximum of $\mathrm{Cu}$ (111) peak than that of the as-deposited sample, which corroborates the decrease in the sheet resistance value presented and discussed above. The $\mathrm{Zr}$ diffraction peaks disappear at a temperature of $800{ }^{\circ} \mathrm{C}$. It is supposed that the $\mathrm{Zr}$ layer may be consumed as a result of the formation of $\mathrm{ZrSi} 2$, which is also a promising diffusion barrier for copper metallization [13]. In addition, the formation of $\mathrm{ZrSi} 2$ decreases the contact resistance between $\mathrm{Si}$ and barriers. The predominant reflection line from $\mathrm{Cu}(111)$ and those from $\mathrm{Cu}(200)$ and $\mathrm{Cu}(220)$ with very weak intensity are observed, which indicates that $\mathrm{Cu}$ film possesses (111) texture. It has been reported ${ }^{[17]}$ that the (111) texture of $\mathrm{Cu}$ films can provide higher electromigration resistance than that of $\mathrm{Cu}(200)$ in $\mathrm{Cu}$ interconnections. In addition, there is no other crystalline phase like $\mathrm{Cu}$ silicide up to $800^{\circ} \mathrm{C}$ and the $\mathrm{Ta}-\mathrm{N}$ amorphous structure is stable in entire annealing process. The XRD results indicate that the $\mathrm{Zr} / \mathrm{Ta}-\mathrm{N}$ barrier can prevent copper diffusion up to $800{ }^{\circ} \mathrm{C}$.

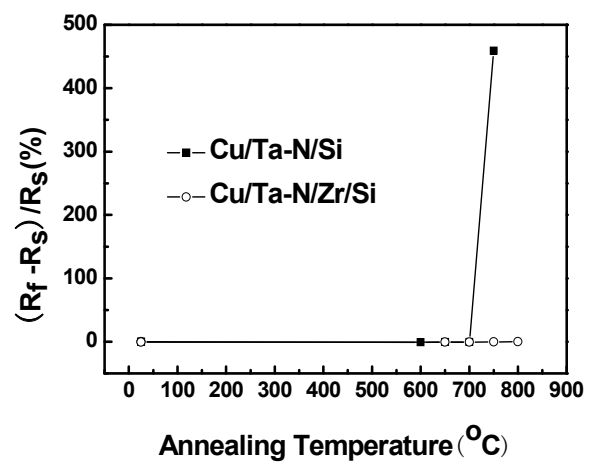

Fig.3. Sheet resistance variation of $\mathrm{Cu} / \mathrm{Ta}-\mathrm{N} / \mathrm{Zr} / \mathrm{Si}$ samples as a function of annealing temperature

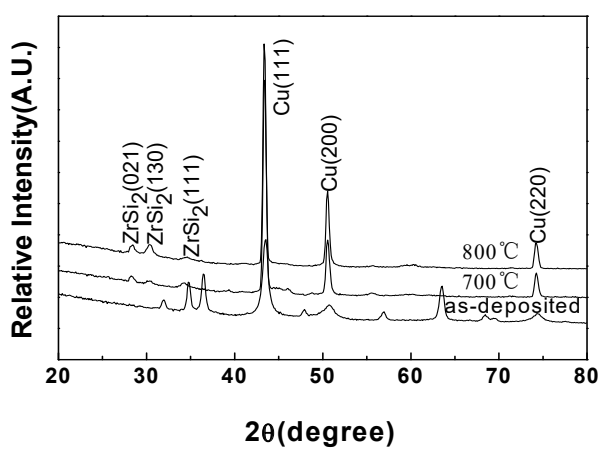

Fig.4. XRD patterns of $\mathrm{Cu} / \mathrm{Ta}-\mathrm{N}(10 \mathrm{~nm}) / \mathrm{Zr}(20 \mathrm{~nm}) / \mathrm{Si}$ samples after being annealed at different temperatures
Fig.5 shows the surface morphologies of $\mathrm{Cu} / \mathrm{Ta}$ $\mathrm{N} / \mathrm{Zr} / \mathrm{Si}$ samples before and after annealing. For asdeposited sample Fig.5(a), the surface is flat without localized defects. After annealed at $700^{\circ} \mathrm{CFig} .5(\mathrm{~b})$, the surface of sample shows $\mathrm{Cu}$ grain growth, which is consistent with XRD result. Annealing at $800^{\circ} \mathrm{CFig} .5(\mathrm{c})$, there are some pinholes in $\mathrm{Cu}$ film and $\mathrm{Cu}$ film is integrated and free from agglomeration. The origin of the pinholes formation is not connected with the $\mathrm{Si}-\mathrm{Cu}$ interaction, but is resulted from thermal stress in the $\mathrm{Cu}$ film itself. In addition, the surface of the sample annealed at $800^{\circ} \mathrm{C}$ is probed by AES and the result is shown in Fig. 5(d). It can be observed there is no $\mathrm{Cu}-\mathrm{Si}$ compound on the surface of sample and the appearance of $\mathrm{C}$ and $\mathrm{O}$ peaks in sample is attributed to the surface contamination and partial oxidation of $\mathrm{Cu}$.
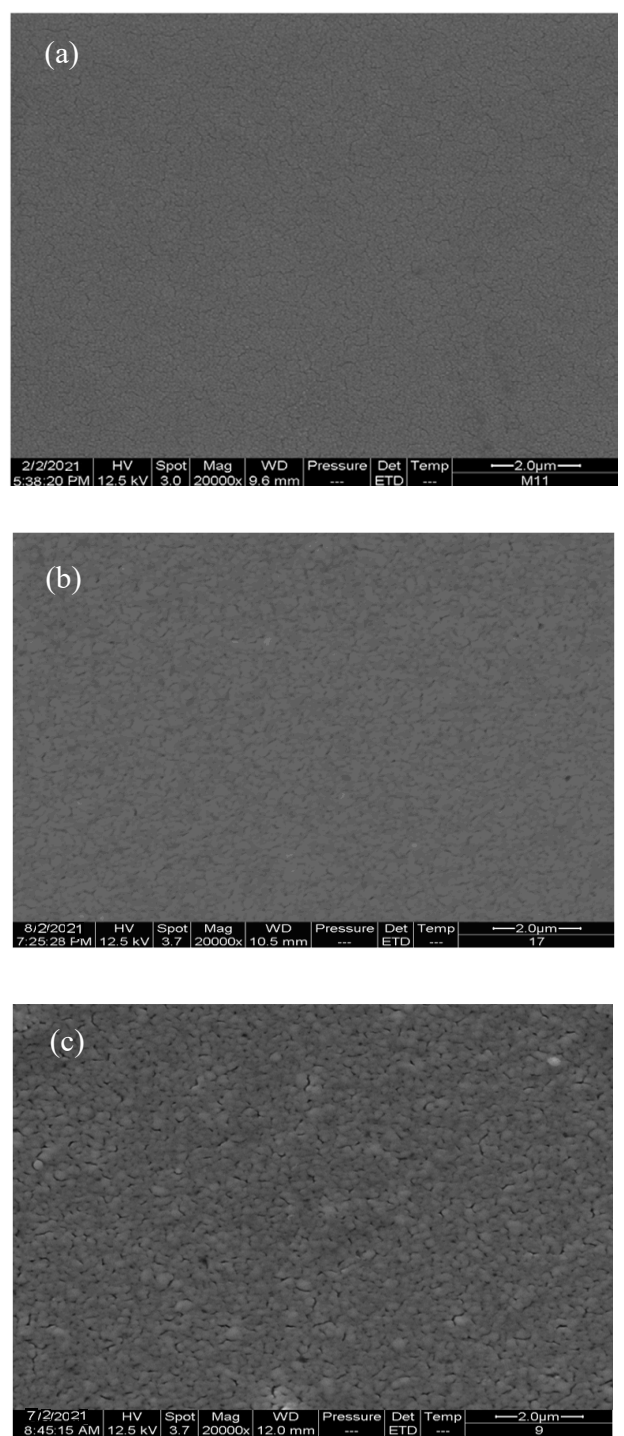


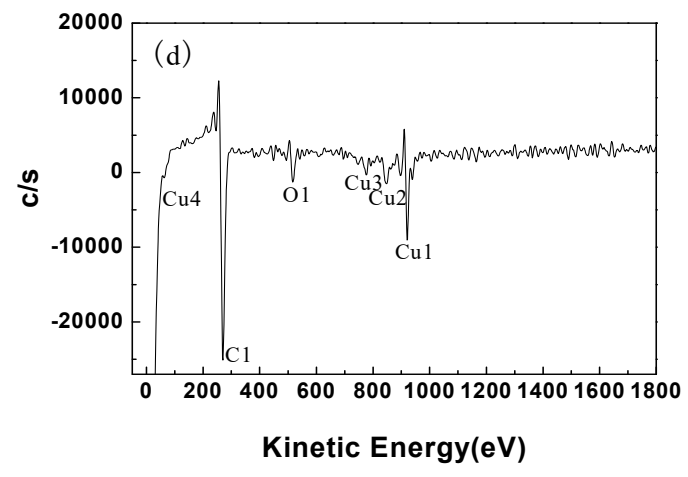

Fig.5. Surface morphologies and surface elements of $\mathrm{Cu} / \mathrm{Ta}-$ $\mathrm{N} / \mathrm{Zr} / \mathrm{Si}$ samples: (a) as-deposited, (b) annealed at $700^{\circ} \mathrm{C}$, (c) annealed at $800^{\circ} \mathrm{C}$, (d) energy spectrum of sample annealed at $800^{\circ} \mathrm{C}$

Fig.6(a) shows the AES depth profile obtained from the as-deposited $\mathrm{Cu} / \mathrm{Ta}-\mathrm{N} \quad(10 \mathrm{~nm}) / \mathrm{Zr} \quad(20 \mathrm{~nm}) / \mathrm{Si}$ specimen. It exhibits a well-separated stacked structure with a sharp transition for all elements at each interface. Fig.6(b) shows the AES depth profiles of the $\mathrm{Cu} / \mathrm{Ta}-\mathrm{N}$ $(10 \mathrm{~nm}) / \mathrm{Zr}(20 \mathrm{~nm}) / \mathrm{Si}$ system upon annealing at $800^{\circ} \mathrm{C}$ for $1 \mathrm{~h}$. A large amount of $\mathrm{Cu}$ still remaines as the asdeposited samples, which demonstrates the integrity of the barrier. Some of the $\mathrm{Zr}$ atoms migrated into the $\mathrm{Si}$ substrate but there was no evidence of $\mathrm{Si}$ migration through the Ta- $\mathrm{N}$ layer into the $\mathrm{Cu}$ layer, which indicates the TaN $(10 \mathrm{~nm}) / \mathrm{Zr}(20 \mathrm{~nm})$ film has excellent diffusion barrier performance and can prevent the diffusion of $\mathrm{Cu}$ atoms up to $800^{\circ} \mathrm{C}$. This agrees well with the results of the XRD, FPP and SEM. The oxygen content in the $\mathrm{Cu} / \mathrm{Ta}-\mathrm{N} / \mathrm{Zr} / \mathrm{Si}$ structures was also investigated by measuring the depth distribution of oxygen in the samples. According to the AES result shown in Fig. 6(a), the as-deposited samples contain a small amount of oxygen. It is also observed that the oxygen is incorporated more with the increasing of the annealing temperature. After annealing at $800^{\circ} \mathrm{C}$, oxygen has gone deep into the $\mathrm{Cu}$ film and Ta-N/Zr layer. The oxygen comes from the residual oxygen in the annealing ambient and deposited chamber. The oxygen distributed in the sample can stuff the grain boundary of barrier and decrease the diffusion paths of $\mathrm{Cu}$ atoms.

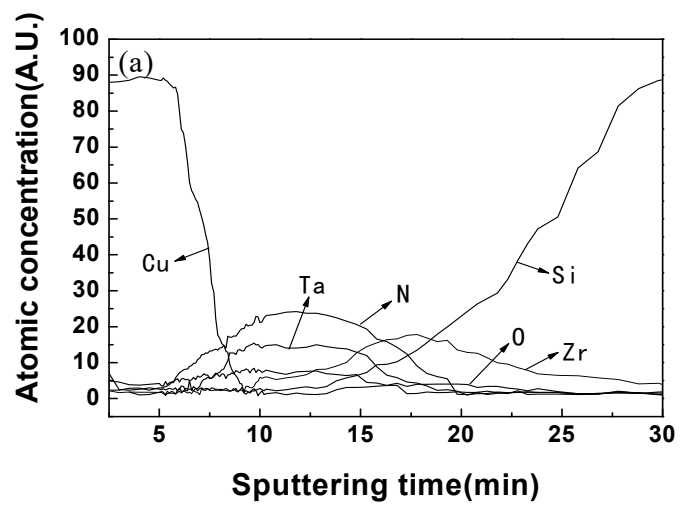

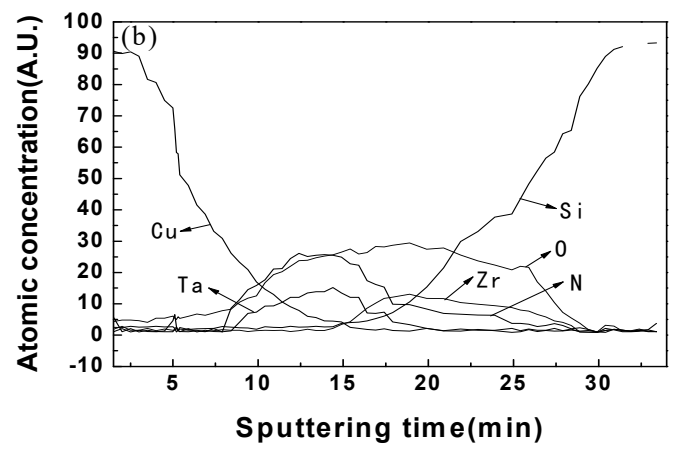

Fig.6. AES depth profiles of $\mathrm{Cu} / \mathrm{Ta}-\mathrm{N}(10 \mathrm{~nm}) / \mathrm{Zr}(20 \mathrm{~nm}) / \mathrm{Si}$ samples: (a) as-deposited and (b) annealed at $800{ }^{\circ} \mathrm{C}$

\section{Conclusion}

In conclusion, the effect of insertion of a thin $\mathrm{Zr}$ layer under Ta-N film on the Ta-N diffusion barrier performance in $\mathrm{Cu}$ metallization has been investigated. It is observed the sheet resistance of $\mathrm{Cu} / \mathrm{Ta}-\mathrm{N}(10 \mathrm{~nm}) / \mathrm{Zr}$ $(20 \mathrm{~nm}) / \mathrm{Si}$ contact system is lower than that of asdeposited specimens even after annealing at $800{ }^{\circ} \mathrm{C}$. XRD data suggest that TaN deposited on $\mathrm{Zr}$ film is the typical amorphous structure and $\mathrm{Cu}$ silicide cannot be obsered up to $800{ }^{\circ} \mathrm{C}$. AES depth profiles of the $\mathrm{Cu} / \mathrm{Ta}$ $\mathrm{N}(10 \mathrm{~nm}) / \mathrm{Zr}(20 \mathrm{~nm}) / \mathrm{Si}$ sample have no noticeable change except $\mathrm{Zr}$ silicide production up to $800^{\circ} \mathrm{C}$. These results indicate that the insertion of a thin $\mathrm{Zr}$ layer into Ta-N film improves the barrier properties significantly. The reason for that is the formation of $\mathrm{ZrSi} 2$ layer, which is also a promising diffusion barrier and can decrease the contact resistance between $\mathrm{Si}$ and barriers. In addition, $\mathrm{Cu}$ films on $\mathrm{Ta}-\mathrm{N} / \mathrm{Zr}$ diffusion barrier prefer the (111) crystal orientation, which indicates that $\mathrm{Cu}(111)$ texture is not inhibited because of the weak interaction at the $\mathrm{Cu} / \mathrm{TaN} / \mathrm{Zr}$ interface. This $\mathrm{Cu}$ (111) texture possess higher electro-migration stability.

\section{References}

1. K. S. Gadre, T. L. Alford, J. W. Mayer, Appl. Phys. Lett. 79 (2001) 3260

2. P. L. Pai, C. H. Ting, IEEE Electron Device Lett. 10 (1989) 423

3. L. Y. WU, M. N. QU, X. C.FU. (2020) Research Progress on Atomic Layer Deposition of $\mathrm{TaN}_{\mathrm{x}}$ Film , Material Reports Vol.34, No. 10, 1910119110

4. S. P. Murarka, Mater. Sci. Eng. R 19 (1997) 87

5. H.C. Chung, C.P. Liu, Surface \& Coatings Technology 200 (2006) 3122

6. G.S. Chen, S. T. Chen, L.C. Yang, P.Y. Lee, J. Vac. Sci. Technol. A 18 (2000) 720

7. G.S. Chen, S. C. Huang, S.T. Chen, T. J. Yang, P. Y. Lee, J. H. Jou, T. C. Lin, Appl. Phys. Lett. 76 (2000) 2895 
8. M. Takeyama, A. Noya, T. Sase, A. ohta, K. Sasaki, J. Vac. Sci. Technol. B 14 (1996) 674

9. G. S. Chen, S. C. Huang, J. Electrochem. Soc. G424 (2001) 148

10. T. Yamauchi, S. Zaima, K. Mizuno, H. Kitamura, Y. Koide, and Y. Yasuda, J. Appl. Phys. 69 (1991) 7050

11. H. Jeon and S. Kim, Jpn. J. Appl. Phys. 37 (1998) 4747

12. J. Y. Cheng and L. J. Chen, J. Appl. Phys. 68 (1990) 4002

13. Y. Wang, F. Cao, Z. X. Song, Electrochemical and Solid-State Letters 10 (2007) H299

14. K. L. Ou, Microelectronic Engineering 83 (2006) 312

15. W. L. Yang, W. F. Wu, D. G. Liu, C. C. Wu, K. L. Ou, Solid-State Electronics 45 (2001) 149

16. Y. L. Kuo, J. J. Huang, S. T. Lin, C. Lee, W. H. Lee, Mater. Chem. Phys. 85 (2004) 444

17. K. Abe, Y. Harada, and H. Onoda, J. Vac. Sci. Technol. B 17 (1999) 1464 